\title{
Experimental Investigation of the Fluid Dynamics of a Finned Heat Sink under Operating Conditions
}

\author{
G. Casano1, M. W. Collins' ${ }^{2}$, S. Piva1 \\ ${ }^{1}$ ENDIF-ENgineering Department In Ferrara, Università di Ferrara, Ferrara, Italia \\ ${ }^{2}$ School of Engineering and Design, Brunel University, Uxbridge, UK \\ Email: giovanni.casano@unife.it, collinmw@hotmail.com, stefano.piva@unife.it
}

Received 7 July 2014; revised 5 August 2014; accepted 5 September 2014

Copyright $@ 2014$ by authors and Scientific Research Publishing Inc.

This work is licensed under the Creative Commons Attribution International License (CC BY). http://creativecommons.org/licenses/by/4.0/

(c) (i) Open Access

\section{Abstract}

An experimental study has been made of the fluid dynamics performance of electronic equipment designed to cool a heat sink in the form of a finned duct. The apparatus consists of a channel of rectangular section containing the finned duct. A forced airflow is driven by three fans placed in parallel in the inlet and in the outlet sections of the channel. In order to investigate a full range of flow rates, different sets of fans were used in the inlet section. Measurements were made of static pressures at different channel positions by pressure taps connected to a micro manometer, and of the flow rate by a Venturi meter. The experimental working conditions of the active fans were consistent with the manufacturers' characteristic curves. Values of the local friction coefficient compared well with published correlations. The experimental working points agreed very well with the theoretical curve of the pressure drop and the hydraulic diameter was demonstrated to be of the appropriate size for this fluid dynamics problem.

\section{Keywords}

Airflow, Duct Flow, Pressure Drop

\section{Introduction}

The cooling systems of a FM power amplifier commonly use forced circulation of air at ambient temperature. These systems, in order to guarantee effective heat transfer, are characterized by wide surfaces of exchange involving finning. However, these large surfaces cause correspondingly high pressure drops, characteristic of such devices. The performance of these heat transfer devices depends on the heat transfer coefficient and on the ve- 
locity of the fluid flowing through the finned duct. One-dimensional models are commonly used for the design of the fluid flow system and for the calculation of the pressure drop. The available schemes for this simplified approach do not cover all the configurations and need to be adapted from similar geometries.

As reviewed by Saini and Webb [1], in the literature, studies mainly focused on two geometries: the duct flow configuration (airflow parallel to the base) and the impinging flow configuration (airflow in at the top and exiting from sides). However, there is a further configuration, not currently studied but often encountered in amplifiers: the case of a finned duct obtained with two opposed heat-sinks so as to create a channel through which the air flows. Figure 1 shows the geometry of the section and the main dimensional characteristics for such a finned duct.

In this design problem it is desirable to use simple models to predict the pressure drop across the finned duct. In the particular case of electronic equipment the heat exchangers are typically short in length and often the condition of fully developed flow is not reached. Since in these applications the length of the heat sink is never of particular importance, the inlet and outlet regions tend to become significant relative to the total length of the duct. This situation has been discussed in depth by Webb [2].

The flow regime in a finned duct used for the above equipment varies from laminar to transition and turbulent flow. For fully developed laminar flow in non circular ducts, basic solutions of the Poiseuille problem are available in the literature [3]. For developing laminar flow in non circular ducts, Muzychka and Yovanovich have proposed a model to determine the apparent [4] and the local friction factor [5]. For turbulent flows less correlations are available [6]. In this case the hydrodynamic entrance length is commonly so short to be less significant than in laminar flow and fully developed correlations are sufficiently accurate.

A review of the literature shows that the non circular sections analysed [1]-[6] are always simpler than the highly complex section addressed in this paper (Figure 1). An important question to answer, is whether the hydraulic diameter, as commonly defined, has significant meaning for this particular geometry.

The present research seeks to address the fluid flow design of this configuration of finned heat transfer device using a one-dimensional approach. The study is experimental: the test section consists of a channel of rectangular section constructed of four plates of PMMA, containing the finned duct. In Figure 2 the experimental equipment is shown.

Measurements of pressure are made at different sections of the finned duct and of air flow rate by a Venturi flowmeter. Three fans are placed at the inlet and three at the outlet of the channel. Figure 3 shows a longitudinal section with the position of the static pressure taps. The experimental data are compared with the results of a model based on correlations commonly used in practice. The data collected are important in validating the one-dimensional model, which is used to optimize the performance of the apparatus.

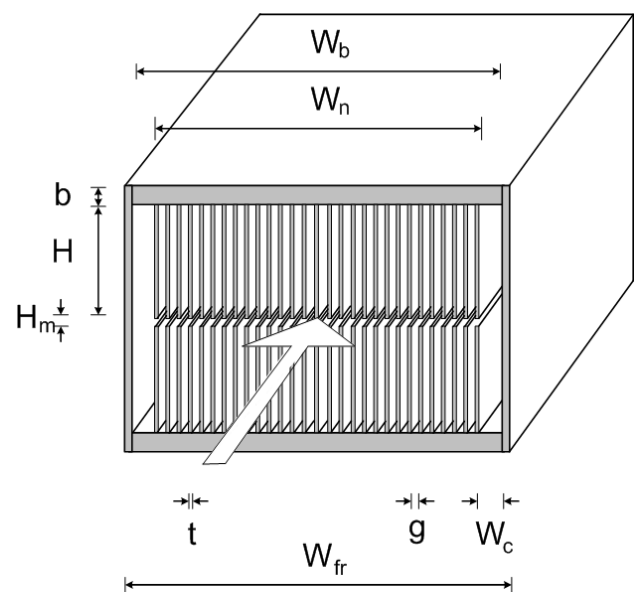

Figure 1. Diagrammatic view of the test geometry with the dimensional characteristics of the passage: $W_{\text {fr }}$, frontal width; $W_{n}$, net width between first and last fin; $W_{b}$, width of the heat sink; $W_{c}$, width of the side duct; $t$, thickness of the fins; $g$, width of the throats; $H$, height of the fins; $H_{m}$, gap between the fins; $b$, thickness of the plates. 


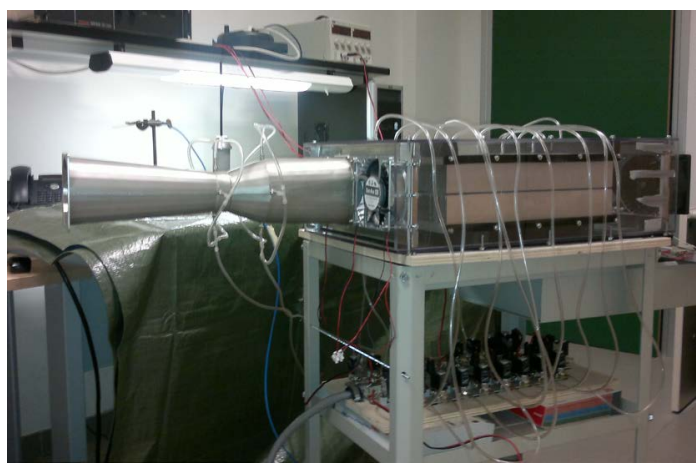

Figure 2. View of the experimental setup.

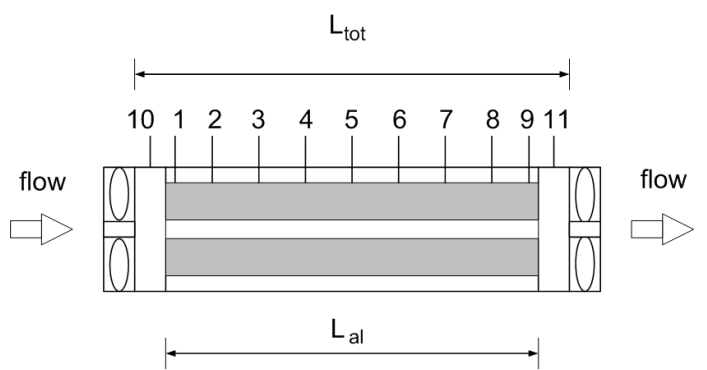

Figure 3. Longitudinal section of the finned duct with the location of the static pressure taps along the test section.

The present experimental work investigates the hydraulic performance of a finned heat sink. Pressure drops are measured as a function of the flow rate. Experimental operating conditions are compared with the rated characteristic curves of the fan. Finally, a comparison between experimental and theoretical friction coefficients is carried out for laminar, transition and turbulent flows.

\section{Experimental Facility}

The experimental apparatus is used to investigate the hydraulic performance of the finned duct. The apparatus itself is designed to replicate as far as possible the flow characteristics of the industrial equipment, which comprises the duct with its finning, and the fans causing the flow of air. The complementary instrumentation is fitted to facilitate the measurement of air pressure drop and flow rate. The tests are carried out under isothermal condition.

Firstly, the finned duct has the same geometry as in the original equipment. The transverse, frontal and longitudinal sections of the duct are shown in Figure 1 and Figures 3-5, respectively. The characteristic dimensions are: $W_{\text {fr }} 380 \mathrm{~mm} ; W_{n} 365 \mathrm{~mm} ; W_{b} 375 \mathrm{~mm} ; W_{s} 5 \mathrm{~mm} ; W_{c} 7.5 \mathrm{~mm} ; 11 \mathrm{~mm} ; g 3 \mathrm{~mm} ; H 48.5 \mathrm{~mm} ; H_{m} 2.4 \mathrm{~mm} ; b$ $14.8 \mathrm{~mm} ; L_{a l} 380 \mathrm{~mm} ; L_{\text {tot }} 400 \mathrm{~mm}$. The number of fins, $N_{t}$, is 91 . The finned duct is inserted into the four-plate PMMA main channel of rectangular section. The channel is $650 \mathrm{~mm}$ long, $170 \mathrm{~mm}$ high and has a width of 380 $\mathrm{mm}$.

Secondly, three fans in parallel are placed both in the inlet and outlet sections of the channel (Figure 4). The inlet fans are active, but to permit flow measurement using a Venturi meter, the exit section fans are inactive. So as to test an experimental range of mass flows for laminar, transition and turbulent regimes, five different sets of inlet fans are used.

In order of increasing performance, the main characteristics of the fans are: Ebm-Papst 4184-NXH (max. airflow $0.067 \mathrm{~m}^{3} / \mathrm{s}$, max. static pressure $\left.160 \mathrm{~Pa}\right)$; NMB-MAT $4715\left(0.085 \mathrm{~m}^{3} / \mathrm{s}, 213 \mathrm{~Pa}\right)$; Sanyo-Denki San Ace 120SG (0.123 m³ $/ \mathrm{s}, 340 \mathrm{~Pa})$; Sanyo-Denki San Ace 120CR $\left(0.142 \mathrm{~m}^{3} / \mathrm{s}, 474 \mathrm{~Pa}\right)$; Ebm-Papst $4114 \mathrm{~N} / 2 \mathrm{H} 8 \mathrm{P}$ $\left(0.158 \mathrm{~m}^{3} / \mathrm{s}, 1251 \mathrm{~Pa}\right)$. To obtain different airflows, the fans are powered at different voltages with a DC power supply Sorensen DCS 55-55. At the outlet the fans are Sanyo San Ace 120SG. 


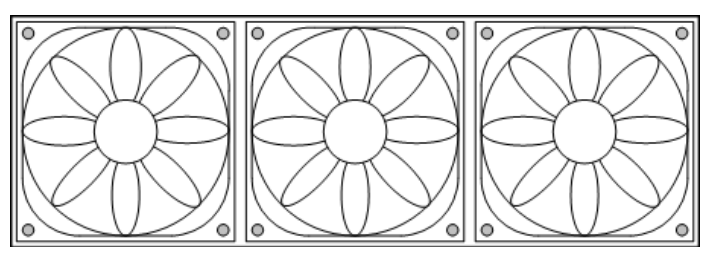

Figure 4. Front view of the fan system.

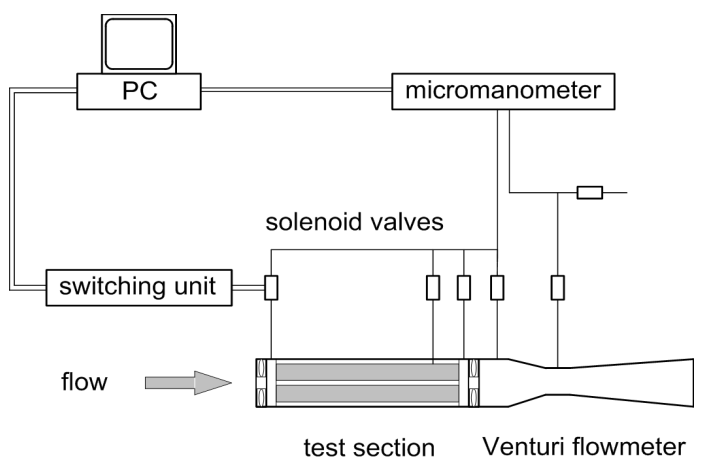

Figure 5. Schematic diagram of the test equipment.

An additional aspect of fan performance in practice is the uniform direction of rotation. As apparent in Figure 4, the left hand and central fans, and the central and right hand fans combine to give counter rotational swirl. Because of lack of commercial availability of counter-rotating fans, it was not possible to investigate the effect on performance of changing the direction of rotation of the central fan.

Finally, the apparatus is fitted with instrumentation for the measurement of flow and pressure. The Venturi meter is positioned with its entrance coincident with the exit from the outlet central fan. The constrained geometry of the Venturi tube, while consistent with practice, is not strictly in accordance with the ISO standard. Its main dimensions are: upstream and downstream pipe diameter $110 \mathrm{~mm}$; throat diameter and length 65.7 and 25 $\mathrm{mm}$, respectively; entrance cone length $65 \mathrm{~mm}$; cylindrical entrance length $160 \mathrm{~mm}$.

Static pressures are measured with nine taps $(\varnothing 1.5 \mathrm{~mm})$ drilled through the top wall of the finned duct. Two further pressure taps are sited in the inlet and outlet calming sections, immediately after and before the fans. The axial position of each pressure tap along the finned channel (the origin of the coordinate system is assumed to be at the inlet of the channel) is specified in Table 1. The inlet and outlet pressure taps are at $-35 \mathrm{~mm}$ and $420 \mathrm{~mm}$ from the origin, respectively. The static pressure holes are connected, through solenoid valves, to a micro-manometer Furness FCO 520. A data acquisition system HP34970A is used as a switching control unit.

The ambient temperature is measured by means of a type $\mathrm{T}$ thermocouple.

The hydraulic diameter is calculated as:

$$
D_{h}=\frac{4 A_{\text {duct }}}{p_{\text {duct }}}
$$

where $p_{\text {duct }}$ is the perimeter of the section. Due to the large number of fins, the hydraulic diameter calculated by means of Equation (1) is $D_{h}=6.3 \mathrm{~mm}$. The finned duct is made of aluminium and the roughness of its surface is $\varepsilon=0.08 \mathrm{~mm}[7]$.

\section{Model}

\subsection{Local Friction Factor}

In laminar flow the local friction factor is calculated, both for fully developed and developing flow, following Muzichka and Yovanovich [5]:

$$
f_{x} \operatorname{Re}_{\text {duct }}=\left[\left(\frac{1.72}{\sqrt{x^{+}}}\right)^{2}+\left(f \operatorname{Re}_{\text {duct }}\right)^{2}\right]^{1 / 2}
$$


Table 1. Axial position of the pressure taps.

\begin{tabular}{ccccccccccc}
\hline Tap number & 1 & 2 & 3 & 4 & 5 & 6 & 7 & 8 & 9 \\
\hline Position $(\mathrm{mm})$ & 5 & 42.5 & 80 & 122.5 & 182.5 & 245 & 285 & 335 & 375 \\
\hline
\end{tabular}

where $f_{x}$ is the local friction factor, $f$ is the friction factor for fully developed flow and $x^{+}$is the dimensionless coordinate:

$$
x^{+}=\frac{x}{D_{h} \operatorname{Re}_{\text {duct }}}
$$

where $x$ is the position along the duct.

The Reynolds number is given by:

$$
\operatorname{Re}_{\text {duct }}=\frac{V_{\text {duct }} D_{h}}{v}
$$

where $v$ is the kinematic viscosity.

The friction factor for fully developed flow is calculated taking as the reference a rectangular channel [3]:

$$
f \operatorname{Re}_{\text {duct }}=24\left(1-1.3553 \beta+1.9467 \beta^{2}-1.7012 \beta^{3}+0.9564 \beta^{4}-0.2537 \beta^{5}\right)
$$

where the channel aspect ratio, $\beta$, is calculated as:

$$
\beta=\frac{g}{\left(2 H+H_{m}\right)} .
$$

The theoretical Darcy friction coefficient for fully developed flow is given by:

while for developing flow it is given by:

$$
\lambda_{t}=4 f
$$

$$
\lambda_{t}=4 f_{x} .
$$

In turbulent flow the equation of Colebrook-White [8] for round pipes is used, where:

$$
\lambda_{t}=\frac{1}{\left(2 \log \left(\frac{\varepsilon / D_{h}}{3.71}+\frac{2.51}{\operatorname{Re}_{\text {duct }} \sqrt{\lambda_{t}}}\right)\right)^{2}} .
$$

\subsection{Pressure Drop}

The resulting pressure drop represents the combined effect of the entrance and exit losses of the duct, developing region effects, the core frictional losses and the exit losses of the channel. Any other pressure drops due to the geometry of the equipment have to be included.

The theoretical pressure drop is the sum of the following components:

$$
\Delta P=\rho \frac{V_{\mathrm{duct}}^{2}}{2}\left(K_{c}+\lambda \frac{L}{D_{h}}+K_{e}\right)+\rho K_{e}^{\prime} \frac{V_{\mathrm{chn}}^{2}}{2}
$$

where $V_{\text {duct }}$ and $V_{\text {chn }}$ indicate the velocity inside the duct and inside the channel, respectively.

For laminar flow Muzichka and Yovanovich [5] have proposed the following relationship for the apparent friction factor:

$$
f_{\text {app }} \operatorname{Re}_{\text {duct }}=\left[\left(\frac{3.44}{\sqrt{L^{+}}}\right)^{2}+\left(f \operatorname{Re}_{\text {duct }}\right)^{2}\right]^{1 / 2} .
$$

The Darcy friction factor, $\lambda$, is then given by:

$$
\lambda=4 f_{\text {app }} .
$$


For turbulent flows Equation (9) is used.

The entrance and exit loss coefficients are calculated as proposed in [8]:

- for laminar flow

$$
\begin{gathered}
K_{c}=0.8-0.4 \sigma^{2} \\
K_{e}=\left(1-\sigma^{2}\right)-0.4 \sigma
\end{gathered}
$$

- for turbulent and transition flow:

$$
\begin{gathered}
K_{c}=0.4\left(1-\sigma^{2}\right) \\
K_{e}=1-\sigma^{2}
\end{gathered}
$$

where $\sigma$ is the ratio between the area of the duct, $A_{\text {duct }}$, and the area of the channel, $A_{\text {chnn }}$.

The exit loss coefficient, $K_{e}^{\prime}$ of the channel is calculated as a function of the passage area of the fans and of the channel [9].

\section{Methodology}

In the present work, the hydraulic performance of the finned duct is studied in terms of pressure drop and friction coefficient for an air flow at ambient temperature. The fans cause a forced motion of the fluid. The finned duct has been tested for a flow range provided by the five different sets of active fans.

Data acquisition starts after the attainment of a steady airflow; $15 \mathrm{~s}$ are sufficient for this aim. An example of the time distribution of pressure drop in the Venturi meter is shown in Figure 6 to confirm the rapid attainment of steady state conditions.

Each data acquisition consists of a substantial number of measurements: one temperature, twelve static pressures and one differential pressure. Furthermore, for each pressure tap fifteen values of pressure are measured by means of the micro-manometer and a statistical analysis of the readings is carried out. Each data acquisition takes ten minutes.

For each data acquisition, the ambient temperature, the gauge static pressure $\left(P_{s t}\right)$ through the channel and the differential pressure in the Venturi meter $\left(\Delta P_{a v}\right)$ are measured. The on/off of the solenoid valves and the following pressure readings are driven by software via a PC.

For flow measurement we use only one Venturi meter after the central fan. The pressure drop introduced by this instrument, while not unappreciable, is small compared with that due to the inactive fans. For this reason, the flow rate measured by means of the Venturi meter is multiplied by three to obtain the total airflow.

Not only so, but the experimental constraints meant that the Reynolds number range in the upstream fell below, and the diameter of the cylindrical entrance were well above, the recommended ISO values. We therefore checked the experimental Venturi parameters with published data of Idelchick [9], enabling a reliable value of the discharge coefficient to be established.

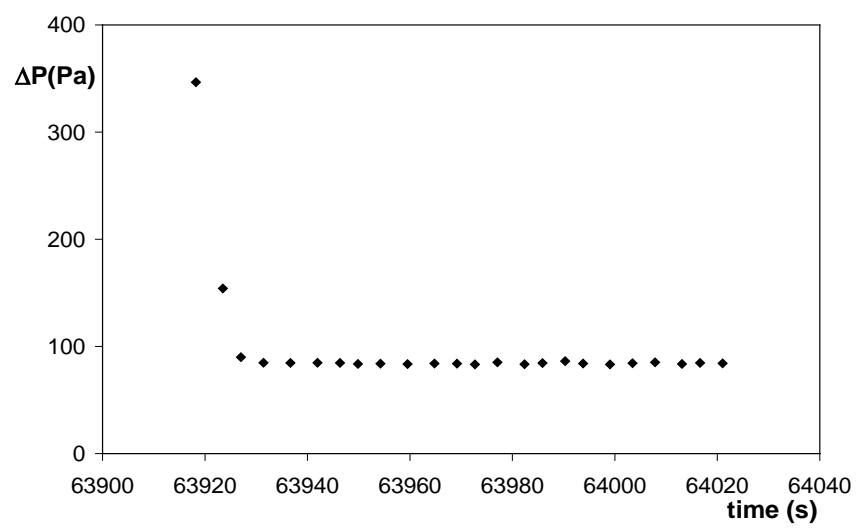

Figure 6. Achievement of steady state: example of pressure drop in the Venturi meter as a function of time. 
In the Venturi meter the mean velocity in the section upstream of the convergent duct is calculated from the measured pressure difference $\left(\Delta P_{a v}\right)$ :

$$
W_{1}=\alpha \sqrt{\frac{2 \Delta P_{a v}}{\rho_{\text {air }}\left(\frac{A_{1}^{2}}{A_{2}^{2}}-1\right)}}
$$

where $\alpha$ is the discharge coefficient, $A_{1}$ is the inlet section area and $A_{2}$ is the throat section area.

The experimental pressure distribution is interpolated in order to obtain the pressure gradient along the duct. These interpolations are performed taking into account the uncertainties both in the dependent and independent variables [10].

The air flow rate and the pressure distribution in the channel allow the experimental values to be obtained of the local Darcy friction factor. This parameter is calculated far from the inlet in order to reduce the effect of the flow development:

$$
\lambda_{\text {exp }}=\frac{2\left(\frac{\mathrm{d} P}{\mathrm{~d} x}\right) D_{h}}{\rho V_{\mathrm{duct}}^{2}} .
$$

The uncertainty of the parameters is estimated at the 95\% confidence level, following the simplified procedure proposed by Moffat [11].

If values of fixed and random errors are available, the overall uncertainty assigned to the measured variable $y$ is given by:

$$
\varepsilon_{y}=\left[\left(B_{\text {inst }}\right)^{2}+(2 \sigma)^{2}\right]^{1 / 2} \text {. }
$$

Otherwise, an overall uncertainty has been estimated on the basis of the manufacturers specifications.

The overall uncertainty assigned to the calculated parameter $P$ is estimated using the root-sum-square propagation rule:

$$
\varepsilon_{P}=\left[\sum_{i=1}^{N}\left(\frac{\partial P}{\partial y_{i}} \varepsilon_{i}\right)^{2}\right]^{1 / 2} .
$$

The relative uncertainty of the flow rate reaches $1 \%$ at maximum, whereas for the Reynolds number is lower than $5 \%$. The local Darcy friction factor is accurate to between $\pm 9 \%$ and $\pm 17 \%$.

The high uncertainty of the local Darcy friction factor is mainly due to the uncertainty of the pressure gradient and less to the velocity in the inlet section of Venturi meter.

\section{Results and Discussion}

Figure 7 shows the relative static pressure distributions inside the finned duct for a series of tests carried out with one model of fan (Sanyo San Ace 120-9SG) supplied with a range of voltages. In Figure 7 the vertical dotted lines indicate the position of the fans and the vertical solid lines the beginning and the end of the finned duct.

The pressure drop in the channel increases for increasing flow rates. With the exception of the entrance, the pressure decreases monotonically along the duct. In the entrance region a stronger pressure drop is evident, in particular for the highest flow rates. As discussed by Webb [2], this behavior can be explained by the further decrease of static pressure due to the recirculation of the fluid close to the wall of the duct in the sudden contraction of the passage area (vena contracta).

A high flow rate also has a clear effect in the outlet section of the finned duct, where the static pressure is lower than in the calming section. This is due to the recovery of static pressure linked to the decrease of fluid velocity in the calming section. This adverse gradient of pressure does not seem enough to produce recirculation near the outlet.

The pressure gauge in the calming section before the inlet of the finned duct, combined with the flow rate, identify the operating conditions of a test. In Figure 8 are shown the overall operating conditions; in the same 


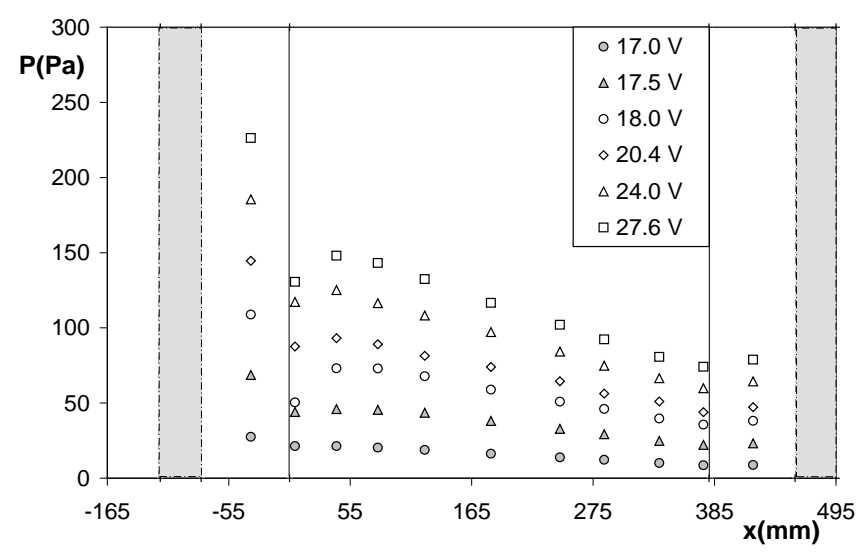

Figure 7. Pressure gauge distribution inside the finned duct.

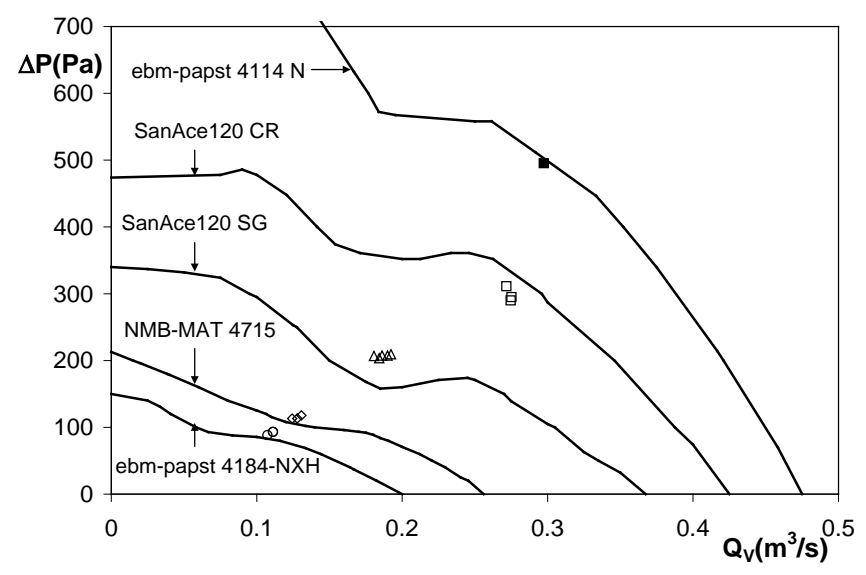

Figure 8. Operating points for different tests carried out on the finned duct.

figure are reported the characteristic curves of the five different fans. There is agreement between the experimental operating conditions and the rated characteristic curves.

In detail, the fans with the lowest performance show a good correlation between the experimental points of work and the fan characteristic curve. The same happens for the most powerful fan. The accordance is lower for the fan SanAce 120 SG; this is probably due to the fact that the working point falls in the instability region of the curve and this makes the reading less reliable. Completely different is the situation for the fan SanAce 120 CR. This is a double fan of very high characteristics. However, the double impeller creates a jet of small diameter (something like a torch) that is unable to diffuse and mix in the calming section at the inlet of the duct. In this situation the static pressure measured at the wall of the calming section is not reliable.

Figure 9 compares experimental values of the Darcy friction coefficient as a function of the Reynolds number with the theoretical values given by Equations (7)-(9).

For low $\mathrm{Re}_{\text {duct }}$ the experimental data are in excellent accordance with theory for fully developed laminar flow. For greater values of $\mathrm{Re}_{\text {duct }}$, the experimental friction coefficients again agree very well with those obtained with the correlation modified for developing laminar flows, Equation (8). Finally, for high values of $\mathrm{Re}_{\text {duct }}$ the experimental data are still in accordance with Equation (9). This very good agreement means that for this large and complex finned duct (Figure 1) the hydraulic diameter is the right parameter to describe the flow behaviour. In spite of the large overall dimension, the hydraulic diameter is closed to that of a rectangular channel $3 \times 99.4$ $\mathrm{mm}$ large, so in the repetition of a micro duct within a macro geometry, the finned duct retains the efficiency of the fundamental repetitive geometry.

Based on the model described in Paragraph 3.2, we calculated the characteristic curve of the overall equipment and compared it with the experimental results. The results are shown in Figure 10. The agreement is par- 


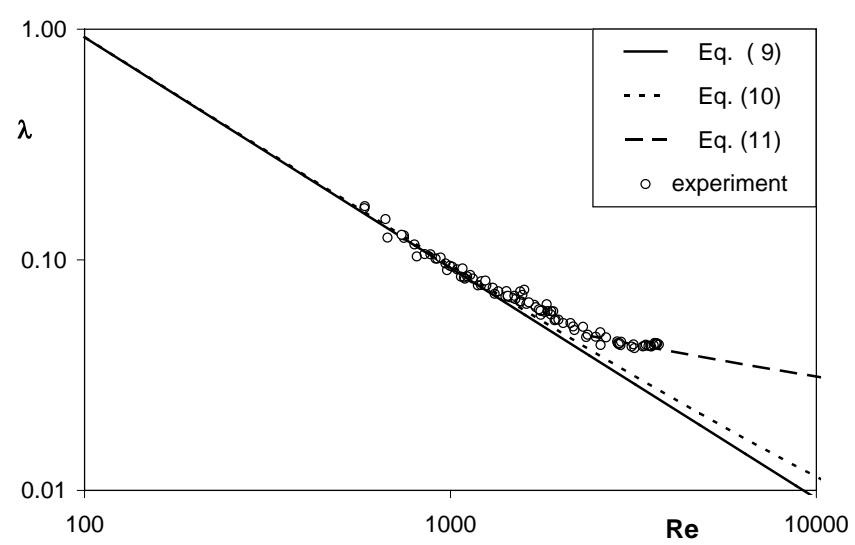

Figure 9. Comparison between theoretical and experimental friction coefficient.

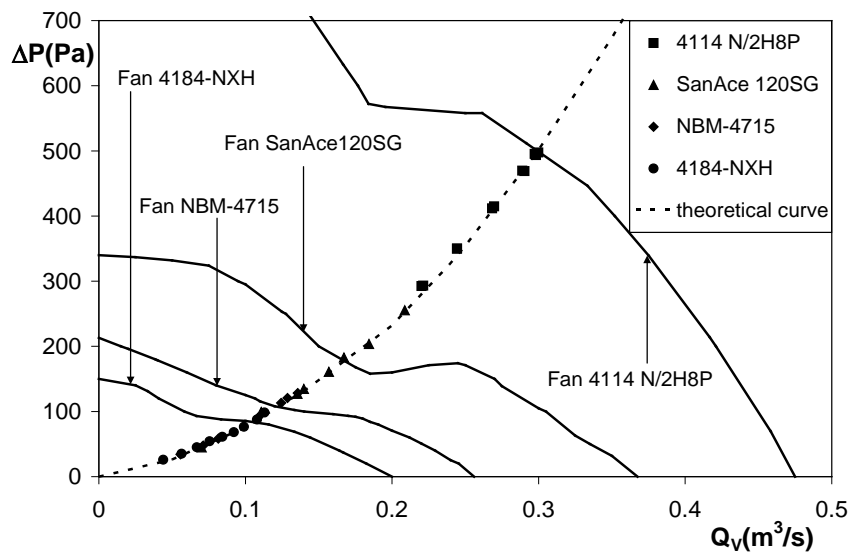

Figure 10. Comparison between theoretical and experimental friction coefficient.

ticularly good. In Figure 10 only four fans are shown because, as already discussed, the double fan SanAce 120 $\mathrm{CR}$ with its torch behaviour does not allow the flow to mix in the inlet calming section and the static pressures measured at the wall of the PMMA channel do not correlate with the flow.

\section{Concluding Remarks}

An experimental investigation has been carried out of the fluid dynamics for a complex finned duct of industrial significance under operating conditions. The experimental working conditions were consistent with the manufacturers' characteristic curves. Useful information has been obtained on the pressure drop curve of the device.

The experimental data of the local friction coefficient show very good accordance with available correlations for the Darcy friction factor.

The experimental working points agree very well with the theoretical curve of the pressure drop.

The hydraulic diameter is demonstrated to be the characteristic dimension appropriate for this complex geometry to obtain the friction coefficient.

\section{Acknowledgements}

This work was funded by ELENOS Spa, which is gratefully acknowledged.

\section{References}

[1] Saini, M. and Webb, R.L. (2002) Validation of Models for Air Cooled Plane Fin Heat Sinks Used in Computer Cool- 
ing. Proceedings of ITHERM 2002, 8th Intersociety Conference on Thermal and Thermomechanical Phenomena in Electronic Systems, San Diego, 1 June 2002, 243-250. http://dx.doi.org/10.1109/ITHERM.2002.1012464

[2] Webb, R.L. (2006) Entrance and Exit Losses for Developing Flow in Parallel Plate Channel. Heat Transfer Engineering, 27, 30-35. http://dx.doi.org/10.1080/01457630600904650

[3] Shah, R.K. and London, A.L. (1978) Laminar Flow Forced Convection in Ducts. Supplement 1 to Advances in Heat Transfer. Academic Press, NY.

[4] Muzychka, Y.S. and Yovanovich, M.M. (1998) Modelling Friction Factors in Non-Circular Ducts for Developing Laminar Flow. Proceedings of 2nd AIAA Theoretical Fluid Mechanics Meeting, Albuquerque, 15-18 June 1998, AIAA Paper No. 98-2492.

[5] Muzychka, Y.S. and Yovanovich, M.M. (2009) Pressure Drop in Laminar Developing Flow in Noncircular Ducts: A Scaling and Modeling Approach. Journal of Fluids Engineering, 131, Article ID: 111105. http://dx.doi.org/10.1115/1.4000377

[6] Ebadian, M.A. and Dong, Z.F. (1998) Forced Convection, Internal Flow in Ducts. In: Rosenhow, W.M., Hartnett, J.P. and Cho, Y.I., Eds., Handbook of Heat Transfer, McGraw-Hill, New York.

[7] White, F.M. (1987) Fluid Mechanics. McGraw-Hill, New York.

[8] Kays, W.M. and London, A.L. (1998) Compact Heat Exchangers. 3rd Edition, McGraw-Hill, New York.

[9] Idelchik, I.E. (1996) Handbook of Hydraulic Resistance. 3rd Edition, Begell House Inc., New York.

[10] Pagliarini, G. and Piva, S. (1993) Thermal Property Estimation by Comparison between Experimental and Analytical or Numerical Solutions. Proceedings of 6th International Conference on Computational Methods and Experimental Measurements, 1, 429-438.

[11] Moffat, R.J. (1994) Establishing the Credibility of Experimental Work. Experimental Thermal and Fluid Science, 8, (Inside Back Cover). 
Scientific Research Publishing (SCIRP) is one of the largest Open Access journal publishers. It is currently publishing more than 200 open access, online, peer-reviewed journals covering a wide range of academic disciplines. SCIRP serves the worldwide academic communities and contributes to the progress and application of science with its publication.

Other selected journals from SCIRP are listed as below. Submit your manuscript to us via either submit@scirp.org or Online Submission Portal.
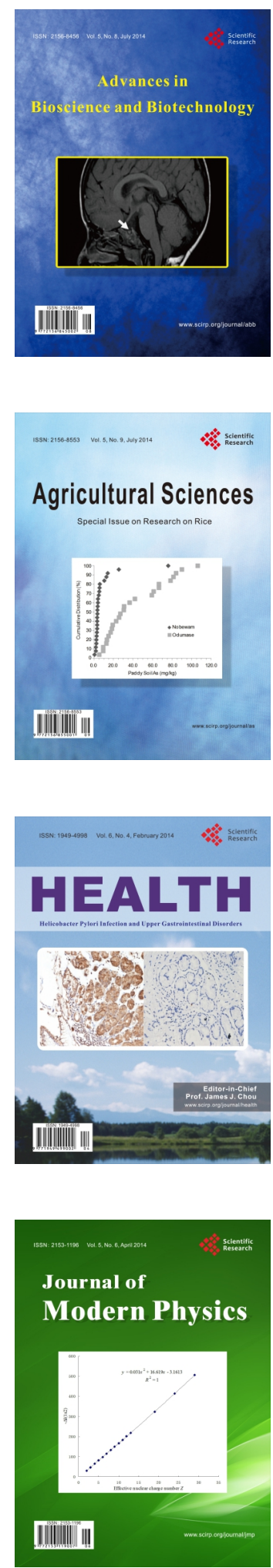
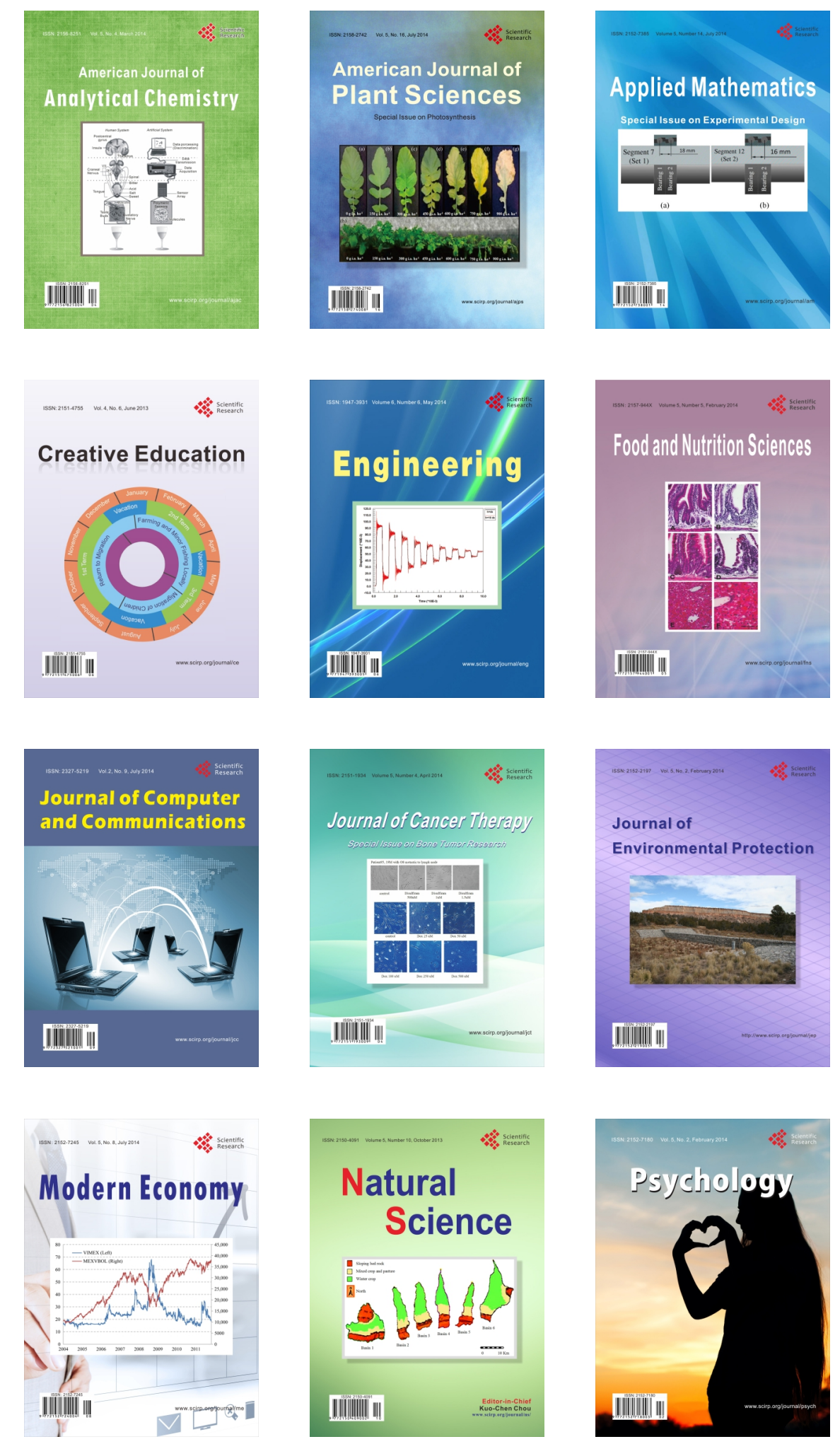